\title{
PERAN SUPERVISI PENDIDIKAN DALAM MENINGKATKAN MUTU BELAJAR
}

\author{
Yuliana \\ e-mail : yuliana290717@gmail.com
}

\begin{abstract}
ABSTRAK :
Supervisi pendidikan mempunyai peran yang sangat penting dalam meningkatkan mutu belajar di sekolah. Supervisi pendidikan dimaksudkan untuk member kemudahan dalam menjalankan setiap program pendidikan yang sesuai dengan standar yang telah ditetapkan dengan memperhatikan tercapainya tujuan berdasarkan penerapannya di lapangan. Pelaksanaan pendidikan perlu penjaminan mutu yang bertujuan untuk memenuhi atau melampaui standar nasional pendidikan. Dimana peserta didik mendapat layanan yang berkualitas dari sekolah dengan seluruh perangkat yang ada didalamnya yang disebut dengan layanan belajar yang berkualitas. Untuk tercapainya pendidikan yang berkualitas diperlukan guru yang professional, berkualitas dan memenuhi syarat kompetensi. Dengan adanya supervisi pendidikan diharapkan dapat meningkatkan mutu belajar di sekolah.

Kata kunci : supervisi, pendidikan, mutu belajar.
\end{abstract}

\section{PENDAHULUAN}

\section{LATAR BELAKANG}

Pelaksanaan pendidikan perlu penjaminan mutu yang bertujuan untuk memenuhi atau melampaui standar nasional pendidikan. Dimana peserta didik mendapat layanan yang berkualitas dari sekolah dengan seluruh perangkat yang ada didalamnya yang disebut dengan layanan belajar yang berkualitas.(Sari, Ngaba, Lalupanda, \& Prastyo Aji, 2017)

Dalam Undang-undang Republik Indonesia Nomor 20 tahun 2003 Bab XI pasal 40 ayat 2b (UU RI, 20/2003; 2003: 27) menjelaskan, "bahwa pendidik dan tenaga kependidikan berkewajiban: mempunyai komitmen secara profesional untuk 
meningkatkan mutu pendidikan". Dengan hal ini, guru merupakan tokoh utama dalam mewujudkan suasana pembelajaran yang kondusif di kelas. Guru yang menciptakan suasana dan keadaan dalam kelas dengan peserta didik.

Untuk tercapainya pendidikan yang berkualitas diperlukan guru yang professional, berkualitas dan memenuhi syarat kompetensi. Menurut Janawi (2012) dalam jurnal (Fitriani, AR, \& Usman, 2017), kriteria yang perlu diperhatikan guru yaitu: 1. Memahami tujuan pelajaran; 2. Mengenali karakteristik peserta didik 3. Membuat tujuan pengajaran 4. Mengenali subyek dan isi setiap materi 5. Mengembangkan alat ukur awal 6. Menyaring kegiatan-kegiatan belajar beserta sumbersumbernya. 7. Mengerahkan layanan-layanan yang mampu mendukung (dana, alat, jadwal); dan mengembangkan alat evaluasi belajar.

\section{RUMUSAN MASALAH}

1. Apa pengertian supervisi pendidikan?

2. Apa saja pendekatan supervisi?

3. Apa fungsi supervisi pendidikan?

4. Apa saja peran supervisi pendidikan?

5. Apa itu mutu pengajaran?

\section{TUJUAN}

Supervisi pendidikan dimaksudkan untuk member kemudahan dalam menjalankan setiap program pendidikan yang sesuai dengan standar yang telah ditetapkan dengan memperhatikan tercapainya tujuan berdasarkan penerapannya di lapangan. (Fauziah, 2017)

\section{PEMBAHASAN}

\section{SUPERVISI PENDIDIKAN}

Secara konseptual, supervisi bermakna pada usaha seorang supervisor untuk mencapai hasil yang diinginkan dengan mendayagunakn bakat/kemampuan alami manusia, dan sumber-sumber yang dapat memfasilitasinya, dengan menekankan pada 
pemberian tekanan dan perhatian yang sebesar-besarnyanya terhadap bakat alami manusia.(Sola, 2018)

Supervisi pendidikan berkembang seiring dengan perkembangan ilmu pengetahuan, teknologi, serta sosial ekonomi dan budaya masyarakat. Supervisi lebih didominasi oleh supervisor dalam bentuk kolaborasi antara supervisor dan guru. Supervisor dan guru bekerjasama dalam meningkatkan kualitas pembelajaran, dan juga untuk membantuguru agar selalu meningkatkan kompetensinya.(Sabandi, 2013)

\section{PENDEKATAN SUPERVISI}

Menurut (Sabandi, 2013) ada beberapa pendekatan supervisi yang popular, yaitu:

a. Supervisi Klinis

Supervisi llinis dilakukan dalam bentuk proses tatap muka yang memungkinkan supervisor dan guru bersama-sama membahas dan menganalisis masalah pembelajaran yang terjadi di kelas dan menemukan mengatasi masalah tersebut.

b. Supervisi Pengembangan

Dalam pendekatan ini supervisor memperlakukan guru sebagai individu yang berada pada berbagai tahap pertumbuhan dan pengembangan. Pendekatan ini didasarkan pada pemikiran bahwa guru memiliki beragam pengalaman, kemampuan, dan tingkat pengembangan karir yang berbeda. Karena itu, supervisor menentukan kebutuhan supervisi guru berdasarkan perbedaan individual, keahlian, dan komitmen. Dengan ini supervisor dapat menggunakan bervariasi pendekatan supervisi untuk guru yang berbeda.

c. Supervisi Diferensial

Menurut Glathorn (1997: 3) dalam (Sabandi, 2013)bahwa supervisi diferensial merupakan pendekatan supervisi yang menyediakan pilihan jenis supervisi dan evaluasi yang sesuai dengan kebutuhan guru. Supervisi diferensial mempertimbangkan perbedaan individual antara guru dan hubungan manusia antara supervisor dan guru.

\section{FUNGSI SUPERVISI}


Agar pembelajaran bermutu, maka supervisinya harus berjalan dengan optimal karena pada kenyataannya proses supervisi sampai saat ini belum berjalan dengan baik dan benar. Supervisi pendidikan dimaksudkan untuk member kemudahan dalam menjalankan setiap program pendidikan yang sesuai dengan standar yang telah ditetapkan dengan memperhatikan tercapainya tujuan berdasarkan penerapannya di lapangan.(Fauziah, 2017)

Menurut (Sutarjo, 2014) hal ini dapat dilihat apabila supervisor, baik itu kepala sekolah atau pengawas melaksanakan seupervisi sebagai berikut:

a. Bukan membantu atau membimbmg melamkan hanya bisa menyalahkan apa yang dikerjakan oleh guru dan tenaga kependidikan lainnya.

b. Memarahi guru atau tenaga kependidikan lainnya jika dalam proses supervisi tidak berjalan dengan lancar, karena ada berbagai kendala.

c. Dalam proses supervisi tidak semua aspek dibantu atau didorong melainkan hanya hal-hal kecuali saja dinyatakan dengan kemampuan yang dimiliki supervisor.

\section{PERAN SUPERVISI PENDIDIKAN}

Tujuan dari supervisi pendidikan adalah memberikan layanan untuk meningkatkan kualitas mengajar guru di kelas agar kualitas belajar siswa di kelas juga meningkat. Menurut (Sutarjo, 2014) secara operasional dapat dikemukakan beberapa peran konkrit dan supervisi pendidikan, yaitu:

a. Membantu guru melihat dengan jelas tujuan-tujuan pendidikan.

b. Membantu guru dalam membimbing pengalaman belajar murid-murid.

c. Membantu guru dalam menggunakan sumber-sumber pengalaman belajar.

d. Membantu guru dalam rnenggunakan metode-metode dan alat-alat pelajaran modern.

e. Membantu guru dalam memenuhi kebutuhan belajar murid-murid.

f. Membantu guru dalam hal menilai kemajuan murid-murid dan hasil pekerjaan guru itu sendiri.

g. Membantu guru dalam membina reaksi mental atau moral kerja gum dalam rangka pertumbuhan pribadi danjabatan mereka. 
h. Membantu guru di sekolah sehingga mereka bergembira dengan tugas yang diperolehnya.

i. Membantu guru agar lebih mudah mengadakan penyesuaian terhadap masyarakat dan cara-cara menggunakan sumber-sumber masyarakat.

j. Membantu guru agar waktu dan tenaga tercurahkan sepenuhnya dalam pembinaan sekolahnya.

\section{MUTU PENGAJARAN}

Mutu pembelajaran adalah suatu kemampuan siswa dalam pengelolaan komponen-komponen yang berkaitan dengan pembelajaran, sehingga menghasilkan nilai tambah terhadap komponen-komponen tersebut menurut standar yang berlaku. Komponen yang berkaitan dengan peningkatan mutu antara lain : siswa, guru, pembina dan pembina sekolah, sarana prasarana proses pengajaran. (Sutarjo, 2014)

Mutu pengajaran sangat ditentukan dari kompetensi yang dimiliki guru. Kompetensi guru dalam mengajar ditentukan dari factor luar dan dalam. Faktor dari dalam antara lain kesehatan, potensi dan kemampuan diri, minat, bakat, sikap dan

kepribadian. Sedangkan faktor dari luar antara lain kepemimpinan kepala sekolah, peserta didik dan sarana prasarana.(Sari et al., 2017)

Kompetensi guru merupakan penguasaan terhadap tugas mengajar yaitu keterampilan, sikap, dan apresiasi yang diperlukan untuk menunjang keberhasilan proses pembelajaran yang dilakukannya. Dengan demikian, kompetensi yang dimiliki oleh setiap guru akan menunjukkan kualitas guru yang sebenarnya. Kompetensi tersebut akan diwujudkan dalam bentuk penguasaan ketrampilan, pengetahuan maupun sikap profesional dalam menjalankan tugas dan fungsi sebagai guru.(Fitriani et al., 2017)

\section{SIMPULAN}

Kesimpulan dari tulisan ini adalah, secara konseptual, supervisi bermakna pada usaha seorang supervisor untuk mencapai hasil yang diinginkan dengan mendayagunakn bakat/kemampuan alami manusia, dan sumber-sumber yang dapat memfasilitasinya, 
dengan menekankan pada pemberian tekanan dan perhatian yang sebesar-besarnyanya terhadap bakat alami manusia.

Mutu pembelajaran adalah suatu kemampuan siswa dalam pengelolaan komponenkomponen yang berkaitan dengan pembelajaran, sehingga menghasilkan nilai tambah terhadap komponen-komponen tersebut menurut standar yang berlaku.

Dengan adanya supervisi pendidikan diharapkan dapat meningkatkan mutu belajar di sekolah.

\section{DAFTAR PUSTAKA}

Fauziah. (2017). Supervisi Pendidikan Sebagai Upaya Peningkatan. Jurnal Tarbiyatuna, 2(1), 36-60. Retrieved from

http://ejournal.kopertais4.or.id/mataraman/index.php/tarbiyatuna/article/download/3206/240 $8 /$

Fitriani, C., AR, M., \& Usman, N. (2017). Kompetensi Profesional Guru Dalam Pengelolaan. Jurnal Magister Administrasi Pendidikan Pascasarjana Universitas Syiah Kuala, 5(2), 8895.

Sabandi, A. (2013). Supervisi Pendidikan Untuk Pengembangan Profesionalitas Guru Berkelanjutan. Jurnal Ilmiah Ilmu Pendidikan, XIII(2), 1-9. Retrieved from http://ejournal.unp.ac.id/index.php/pedagogi/article/view/4275

Sari, S. I., Ngaba, A. L., Lalupanda, E. M., \& Prastyo Aji, A. G. (2017). Pengendalian Dan Penjaminan Mutu Pengajaran Melalui Supervisi Klinis. Satya Widya, 33(1), 1. Retrieved from http://ejournal.uksw.edu/satyawidya/article/download/868/634/

Sola, E. (2018). Ada Apa Dengan Supervisi Pendidikan? Jurnal Idaarah, II(1), 130-140.

Sutarjo. (2014). Supervisi Pengawas Dan Kepala Sekolah Dalam Peningkatan Mutu Pembelajaran (Studi Kasus Pada Sma Negeri Di Kabupaten Karawang). Jurnal Pendidikan Unsika, 2(1), 105-117. Retrieved from https://journal.unsika.ac.id/index.php/judika/article/view/126 